\title{
GAMIFICATION APPROACH TO ENHANCE STUDENTS ENGAGEMENT IN STUDYING LANGUAGE COURSE
}

\author{
Andharini Dwi Cahyani \\ Informatics Department., Faculty of Engineering, \\ University of Trunojoyo Madura \\ E-Mail: andharini.dwi.cahyani@gmail.com
}

\begin{abstract}
Many researchers have attempted to utilize gamification to increase student engagement, motivation and achievement in the classroom with varying degrees of accomplishment. This research attempts to review of existing literature on the subject as well as the implementation of gamification on Language course. It aims to get better understanding of how gamification can efficiently be used in education. This analysis reveals that the underlying fact that make games engaging are already utilized in pedagogical practices. There are two important recommendations from this research. First, use gamified learning scenario as an activity, to encourage students trying new things and avoiding fear to make a mistakes. Secondly, the gamification in education setting needs students to participate deliberately to ensure the gamification retains the game-like nature.
\end{abstract}

Keywords: gamification, enjoyment, motivation, engagement

\section{INTRODUCTION}

For students, Language is a course that can be very challenging. This work is aimed to use gamification to help students understand the Madurese language more thoroughly, as well as to make the learning of the topic more fun and engaging. Successful and efficient educational applications have a similar relation to instruction, goals, feedback and interaction. Unfortunately, many educators find it difficult to implement strategies in their curriculum to compete with the engagement of computer games.

\section{Background}

Gamification is currently adopting the game elements to improve user experience and user engagement, specifically in non-game contexts (Groh, 2012). Anderson and Rainie's (2012) report defined gamification as the online interactive system design that occupy on people's competitive instincts and rewards to motivate the player. Rewards may be virtual rewards, such as payments, points, badges, or free gifts. According to (McGonigal, 2011), people worldwide spend 3 billion hours a week playing video and computer games. Therefore, it would be potential to make the students' practice for their language skill and knowledge instead of perfecting their skill in "Clash of Clans" strategies.

Many researchers studied the relationship between gamification with in-class participation, students' motivation and student's engagement. Thamvichai et.al. (2012) implemented a points-based system in an attempt to integrate game mechanics into an engineering curriculum. Through the use of a quick questionnaire, the researchers found students motivated to engage in the given tasks. At the same year, Cronk
(2012) also adopted gamification concept as a reward-based system in the form of a virtual tree that would get bigger relates to students' points/score. This study also reported an increase in an in-class students' participation. Sheldon (2011) also implemented gamification concept in the classroom. In his experiments, the students are divided into guilds and compete to gain experience points (XP). At the end of the semester, the XP is translated into letter grades. This study reported that the students are pleasing to the class participation.

\section{Educational Games}

It is believed that nature of games may facilitate students' engagement and involvement, motivation and interest, and the retention of learned skills. More recently, it has also been suggested that players of commercial games are developing problem solving and literacy skills (Urh et al, 2015). It means that the good commercial games have good learning principles that provide opportunities for gamers to engage and improve their skills during gameplay. Furthermore, Barab and Dede (2007) stated that the "immersive" nature of educational games have the potential to transform the school content standards knowledge into "just-in-me" knowledge to solve meaningful problems actively and interactively.

Lee and Hammer (2011) stated that there are three reasons why the game-like elements have a high engagement in high schools and institutions of higher education. First, the players who usually use different avatars, such as the act as a fantasy character or a secret agent, is proven to be successful in schools (Nasir and Saxe, 2003). This fact leads to experiences of social credibility and recognition. 
Second, good game designs perfectly match the player's cognitive abilities with the difficulty level. For example, good games present personalize tutorials while keeping players' engaged and motivated. Moreover, good games usually have incremental sub-goals and also alternative ways to solve its problem that is can be very challenging and motivating. This situation answers the challenges of the educational system nowadays that is student motivation and engagement (Bridgeland et al., 2006).

Third, games especially simulations, are perfectly-fitting sandboxes that allow students to learn from mistakes in quick recovery. Games and simulations enable students to see failures as an opportunity to learn along with frequent feedback cycles. As a result, the students cover an important emotional problem faced in traditional institutions, such as the excessive demand to pass a final exam, or to fail the course.

\section{METHODOLOGY}

In this study, the effect of the gamified learning activity was analyzed along three dimensions: perceived easy to use, engagement, and motivation. There are totally 30 students participating in this study, of which 18 are male and 12 female, with the average age of 6-8 years.

\section{Gamification in Education : enjoyment, engagement, motivation}

Gamification is a strategy to design the engagement power of games in a non-gaming context (e.g., industry, education, etc.). Others have emphasized the fact that gamification is implemented through technology. For example, Domínguez et al. (2013) defined gamification as "incorporating game elements into a non-gaming software application to increase user engagement and experience". This definition appears more specific and also includes the purpose of gamification as fostering engagement in studying. Prior scholars have defined the educational participation as a bound in learning process (Filsecker and Hickey, 2014), committed learning (diSessa, 2000), and intentional learning (Scardamalia et al, 1989). Therefore, we may conclude that gamification is brought up the enjoyment while studying by fostering students' engagement and students' motivation.

In the gamification literature, usually we found game elements, for example, rewards systems and the use of badges for displaying achievement (Landers and Callan, 2011). This badge is an "informal way" to offer a learning certificate (Abramovich et al., 2013). The badges on the learners' profile are viewable by other players and are awarded for either incidental activity or mastery of skills/demonstration of knowledge. In other words, badges may symbolize a learner's participation and performance (Simões, et al,, 2013).

Some researchers have adopted gamification concept to their prior e-learning system. For example, Schoooools.com for K-6 (Simões et al., 2013), casual social games for undergraduate education and employee training (Landers and Callan, 2011) and, intelligent-tutor-systems (Abramovich et al., 2013). In Landers and Callan (2011) experiments, there is a social experiment where the college students have to answer small quiz and based on their score, the students would be ranked and provided with badges indicating their performance level. There are five performance levels, namely: "Newbie", "Novice", "Intermediate", "Expert" and "Master". These badges are viewable by others on the students' profile. A preliminary evaluation of this project regarding student's motivation presented that a considerable number of students used the gamification features and that by doing so taking the quiz seemed to the more enjoyable and rewarding activity.

Abramovich et al. (2013) introduced gamification in the context of an intelligent tutor system. In gamification learning scenario, the badges were awarded based both on individuals mastery of a skill and on their participation in the system. After using the intelligent tutor system, which use gamification learning scenario - they found that the students showed less concerned about poor performance as compared to their peers and more interest in learning language. Therefore, in summary, research on gamification has just begun, and questions related to their impact on learning, students' motivation and engagement needs a systematic exploration. This study represents an empirical exploration of the relationship between enjoyment, motivation, engagement while studying in gamification learning scenario.

\section{Application Design}

Gamification has been used in many contexts, from military training (Halter, 2006) and education (Kapp, 2012) to service marketing (Huotari and Hamari, 2012). In this research, we build gamification in Language course for 6th grades with five learning modules. This user leveling in this application is based on the students knowledge. There are three user levels for each module, namely "beginner", "intermediate" and "advanced". Each level contains three core steps, which are: doing pre-test, learning the material and doing exercise. The pre-tests' result presents the user level at the current module. The detailed of this gamification learning scenario is as Figure 1. 


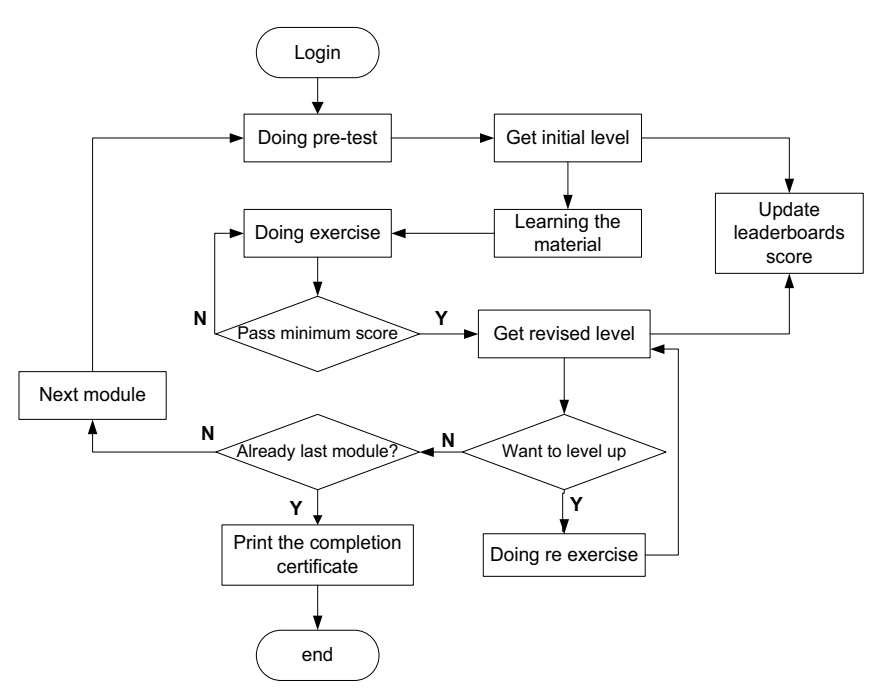

Figure-1. Application Learning Scenario

After doing pre-test, the application calculates the score and obtain the a user initial level. In the meantime, the leaderboards score for that specific level is also updated. User level represents the "students' badges". Furthermore, to be specific, there is a score for each "students' badges" within leaderboards score.

After getting to the initial level, the user should follow the learning material instruction and do some exercise. If he/she passes the minimum score, then he/she gets revised level and also the system update the leaderboards score. Also, the user may level up by doing re exercise and get the revised level. This scenario applies to all modules, so when a user is already in the last module, the application made a completion certificate.

\section{RESULTS}

In this study, the effect of the gamified learning activity was analyzed along three dimensions: perceived easy to use, engagement, and motivation. There are totally 30 students participating in this study, of which 18 are male and 12 female, with the average age of 6-8 years. For each of these dimensions, participants indicated their agreement or disagreement on a 5-point Likert scale (strongly disagree, disagree, neither agree or disagree, agree, strongly agree) to a number of related statements. The results for each dimension are discussed next in details.

\section{Enjoyment}

An important effect of gamification is that the application should be enjoyable. Furthermore, the enjoyment of the application can lead to improved learning. Therefore, it was important to know how the students enjoy the gamified learning activity. Statements related to enjoyment are presented in Table-1.
Table-1. Statements related to students enjoyment

\begin{tabular}{|l|l|}
\hline No & Description \\
\hline 1 & I feel genuinely fun \\
\hline 2 & I feel happy when playing the game \\
\hline 3 & I feel that it is great for killing time productively \\
\hline 4 & I feel exhausted when playing it \\
\hline 5 & I feel miserable when playing it \\
\hline
\end{tabular}

\section{Engagement}

An important effect of gamification is that the application can engages the student to the learning material. The student were not only learning what their schools offer but also trying to understand and also internalizing the material towards their life (Newmann, 1992). Gamification within learning process allows students to fail and not feel rejected, so they are willing to try more and more. Statements related to engagement are presented in Table-2.

Table-2. Statements related to students engagement

\begin{tabular}{|l|l|}
\hline No & Description \\
\hline 1 & $\begin{array}{l}\text { I wanted to explore all the options because it was } \\
\text { very challenging }\end{array}$ \\
\hline 2 & I felt that time passed quickly \\
\hline 3 & I wanted to complete the game \\
\hline 4 & I did not care how the game ended \\
\hline 5 & I feel bored when playing it \\
\hline
\end{tabular}

\section{Motivation}

Students' motivation plays an important role towards conceptual change processes within the affective components, critical thinking, learning strategies and learning achievement. When students have determined their achievement goal, they are intrinsically motivated. Therefore, the students intend to accomplish something to satisfy their innate needs for improving their own performance (Ryan et al., 1991). We suggest that gamified learning interventions may enhance student motivation in their learning process.. Statements related to engagement are presented in Table-3.

Table-3. Statements related to students motivation

\begin{tabular}{|l|l|}
\hline No & Description \\
\hline 1 & It was important to me to do well at this task \\
\hline 2 & I would describe this activity as very interesting \\
\hline 3 & I tried very hard on this activity \\
\hline 4 & I didn't try very hard to do well at this activity \\
\hline 5 & I didn't put much energy into this \\
\hline
\end{tabular}


The response of students is summarized in Table-4. It appears that the majority of students felt enjoyed, engaged and motivated through this gamification learning scenario.

Table-4. Summarized result of the questionnaire

\begin{tabular}{|c|c|c|c|c|c|c|}
\hline No & Question & $\begin{array}{l}\text { Strongly } \\
\text { Disagree }\end{array}$ & Disagree & Neither & Agree & $\begin{array}{l}\text { Strongly } \\
\text { Agree }\end{array}$ \\
\hline \multicolumn{7}{|c|}{ Statement related to enjoyment } \\
\hline 1 & I feel genuinely fun & $0 \%$ & $10,000 \%$ & $20,000 \%$ & $33,333 \%$ & $36,667 \%$ \\
\hline 2 & I feel happy when playing the game & $3,333 \%$ & $10,000 \%$ & $16,667 \%$ & $36,667 \%$ & $33,333 \%$ \\
\hline 3 & $\begin{array}{l}\text { I feel that it is great for killing time } \\
\text { productively }\end{array}$ & $6,667 \%$ & $10,000 \%$ & $16,667 \%$ & $30,000 \%$ & $36,667 \%$ \\
\hline 4 & I feel exhausted when playing it & $20,000 \%$ & $36,667 \%$ & $20,000 \%$ & $13,333 \%$ & $10,000 \%$ \\
\hline 5 & I feel miserable when playing it & $43,333 \%$ & $30,000 \%$ & $20,000 \%$ & $6,667 \%$ & $0 \%$ \\
\hline \multicolumn{7}{|c|}{ Statement related to engagement } \\
\hline 6 & $\begin{array}{l}\text { I wanted to explore all the options } \\
\text { because it was very challenging }\end{array}$ & $0 \%$ & $6,667 \%$ & $10,000 \%$ & $50,000 \%$ & $33,333 \%$ \\
\hline 7 & I felt that time passed quickly & $6,667 \%$ & $20,000 \%$ & $26,667 \%$ & $16,667 \%$ & $30,000 \%$ \\
\hline 8 & I wanted to complete the game & $3,333 \%$ & $6,667 \%$ & $16,667 \%$ & $46,667 \%$ & $26,667 \%$ \\
\hline 9 & I did not care how the game ended & $33,333 \%$ & $36,667 \%$ & $13,333 \%$ & $10,000 \%$ & $6,667 \%$ \\
\hline 10 & I feel bored when playing it & $6,667 \%$ & $10,000 \%$ & $10,000 \%$ & $40,000 \%$ & $33,333 \%$ \\
\hline \multicolumn{7}{|c|}{ Statement related to motivation } \\
\hline 11 & $\begin{array}{l}\text { It was important to me to do well at } \\
\text { this task }\end{array}$ & $3,333 \%$ & $6,667 \%$ & $13,333 \%$ & $36,667 \%$ & $40,000 \%$ \\
\hline 12 & $\begin{array}{l}\text { I would describe this activity as } \\
\text { very interesting }\end{array}$ & $3,333 \%$ & $6,667 \%$ & $16,667 \%$ & $30,000 \%$ & $43,333 \%$ \\
\hline 13 & I tried very hard on this activity & $40,000 \%$ & $26,667 \%$ & $13,333 \%$ & $10,000 \%$ & $10,000 \%$ \\
\hline 14 & $\begin{array}{l}\text { I didn't try very hard to do well at } \\
\text { this activity }\end{array}$ & $33,333 \%$ & $23,333 \%$ & $10,000 \%$ & $10,000 \%$ & $23,333 \%$ \\
\hline 15 & I didn't put much energy into this & $30,000 \%$ & $26,667 \%$ & $13,333 \%$ & $10,000 \%$ & $20,000 \%$ \\
\hline
\end{tabular}

Regarding to enjoyment questions, $33.33 \%$ of participants agreed and $36.67 \%$ strongly agreed (a total of $70 \%$ ) that they had fun while studying in this gamification learning scenario. When asked aboutthe opposite, i.e., if they were exhausted while studying in this gamification learning scenario, 36.67\% disagreed and $20 \%$ strongly disagreed (a total of $56.67 \%$ ). While there is some ambivalence about the participants' feelings of enjoyment while studying in this gamification learning scenario, it seems that most felt some degree of enjoyment while a small number of participants did not specifically enjoy the activity.

When asked if the students were feel challenged in this gamified learning activity, the majority of participants answered that they were engaged enough to explore all the options $(83.33 \%)$ and only $16.67 \%$ felt bored when playing it. More than half of the participants $(73.33 \%)$ wanted to complete this gamified learning activity and slightly less than half found that time passed quickly during the gamification (46.67\%). Only $16.67 \%$ stated they did not care how this gamification is ended.

This research also revealed if gamified learning scenario may increase students' motivation. The overall responses were positive: $76.67 \%$ of participants felt that it is important for them to do well at this task, and 
$73.33 \%$ believed that this activity is interesting. When asked about the opposite, i.e., if they didn't very hard to do well at this activity, $23.33 \%$ disagreed and $33.33 \%$ strongly disagreed (a total of $56.67 \%$ ).

\section{DISCUSSION}

The results of the study have a positive impact, particularly on enhancing learning, which is the primary objective of the work. The majority of participants felt that the gamified learning activity improved their learning. Furthermore, the activity did engage the participants and result in some degree of enjoyment.

There are two important recommendations to ensure that the gamified activity retains its game-like feel. The recommendations are: (1) use gamification as an activity, and (2) students' participation should be optional. If we use this as an assessment or students are forced to undertake it, then it will reduce students' motivation to complete it. Students will see it likely as another learning task and takes away from its game-like nature.

One of our intentions in the development of the gamified learning activity was to develop an approach and supporting tool that is not discipline-specific. However, so far, it has only been trialled in Language subject. Trials in courses from other disciplines would be useful to ascertain that the approach and tool are non-discipline specific.

Our proposed work is aimed to investigate how gamified learning approach influence students engagement and motivation during the learning process. This approach was trialed in 6th grade of Elementary School. To evaluate this approach, 30 participants have completed the questionnaire survey that has three dimensions, namely: enjoyment, engagement, and motivation. We found that $70 \%$ members believe that they feel happy while doing gamified learning activity. Furthermore, $73.33 \%$ believe that this activity is very interesting, and $83.33 \%$ perceived that doing gamified learning activity makes them feel challenged and want to complete and master all level.

These results present that this implementation of gamified learning scenario has substantial influence and deserve further researched. Moreover, the students' participation should be voluntary to ensure that the gamification retain as a "game-like" activity. Therefore, students will be encouraged to try new things and overcome the fear of making mistakes. Students who are enthusiastic to participate in this gamification also will be engaged in enjoyable experiences in the learning activity.

\section{CONCLUSION}

A gamification is an innovative approach to education that is continuously emerging. Future studies should investigate the new mechanics and new applications associated with emerging gamification technologies.

The results of this survey presented that the gamification can have a positive effect on learning. However, it should be remarked that these findings are about one particular implementation of gamification in education. Further research is needed to discover if gamification improves learning to use a variety of methods and to determine other ways gamified activity in school.

\section{ACKNOWLEDGMENT}

We would like to thank the students and academics for their involvement in this study. This study was supported and funded by Engineering Faculty of Universitas Trunojoyo Madura - Indonesia.

\section{REFERENCES}

Abramovich, S., Schunn, C., \& Higashi, R.M. 2013. Are Badges Useful in Education?: It Depends Upon The Type Of Badge And Expertise Of Learner. Educational Technology Research and Development, 61, 217-232.

Anderson, J., \& Rainie, L. 2012. Gamification And The Internet: Experts Expect Game Layers To Expand In The Future, With Positive And Negative Results. Games For Health : Research, Development, and Clinical Applications, 1(4), 299-302.

Barab, S., \& Dede, C. 2007. Games And Immersive Participatory Simulations For Science Education: An Emerging Type Of Curricula. Journal of Science Education and Technology, 16(1), 1-3.

Bridgeland, J. M., DiIulio Jr, J. J., \& Morison, K. B. 2006. The Silent Epidemic: Perspectives Of High School Dropouts. Civic Enterprises.

Cronk, M. 2012. Using Gamification To Increase Student Engagement And Participation In Class Discussion. In World Conference on Educational Multimedia, Hypermedia and Telecommunications 2012 (1), 311-315.

diSessa, A. A. 2000. Changing Minds: Computers, Learning and Literacy. Cambridge, MA: MIT Press.

Domínguez, A., Saenz-de-Navarrete, J., De-Marcos, L., Fernández-Sanz, L., Pagés, C., \& Martínez-Herráiz,J. 2013. Gamifying Learning Experiences: Practical Implications and Outcomes. Computers \& Education, 
$63,380-392$.

Filsecker, M., \& Hickey, D. T. 2014. A Multilevel Analysis Of The Effects Of External Rewards On Elementary Students' Motivation, Engagement And Learning In An Educational Game. Computers \& Education, 75, 136-148.

Groh, F. 2012. Gamification: State of The Art Definition And Utilization. Institute of Media Informatics Ulm University, 39.

Halter, E. 2006. From Sun Tzu to Xbox: War and Videogames. Thunder's Mouth Press, New York.

Huotari, K., \& Hamari, J. 2012. Defining Gamification: A Service Marketing Perspective. In Proceeding of the 16th International Academic MindTrek Conference. $17-22$.

Kapp, K.M. 2012. The Gamification Of Learning And Instruction: Game-Based Methods And Strategies For Training And Education. John Wiley \& Sons.

Landers, R. N., \& Callan, R. C. 2011. Casual Social Games As Serious Games: The Psychology Of Gamification In Undergraduate Education And Employee Training. In Serious Games And Edutainment Applications. 399-423. Springer London.

Lee, J. J., \& Hammer, J. 2011. Gamification in education: What, How, Why Bother?. Academic Exchange Quarterly, 15(2), 146.

McGonigal, J. 2011. Reality is broken: Why Games
Make Us Better And How They Can Change The World. Penguin.

Newmann, F.M. 1992. Student Engagement and Achievement in American Secondary Schools. Teachers College Press.

Ryan, R. M., Edward L., and Deci. 1991. A Motivational Approach to Self: Integration in Personality. Perspectives On Motivation, 38, 237.

Scardamalia, M., Bereiter, C., McLean, R. S., Swallow, J., \& Woodruff, E. 1989. Computer-Supported Intentional Learning Environments. Journal of Educational Computing Research, 5(1), 51-68.

Sheldon, L. 2011. The Multiplayer Classroom: Designing Coursework As A Game. Boston, MA: Course Technology Press.

Simões, J., Díaz, R., \& Fernández, A. 2013. A social gamification framework for a K-6 learning platform. Computers in Human Behavior, 29, 345-353.

Thamvichai, R., \& Supanakorn-Davila, S. 2012. A pilot study: Motivating students to engage in programming using game-like instruction. Proceedings of Active Learning in Engineering Education. St. Cloud University.

Urh, M., Vukovic, G., \& Jereb, E. 2015. The model for introduction of gamification into e-learning in higher education. Procedia-Social and Behavioral Sciences, 197, 388-397. 